\title{
Environmental triggers of COPD symptoms: a cross sectional survey
}

\author{
Susan R. Sama ${ }^{1,2^{*}}$, David Kriebel ${ }^{1}$, Rebecca J. Gore ${ }^{1}$, Rebecca DeVries ${ }^{1}$ and Richard Rosiello
}

\begin{abstract}
Background: There is little published evidence on environmental triggers of COPD exacerbation, despite anecdotal reports from patients and clinicians. This study gathered data on reported triggers of COPD exacerbation among a well-characterized cohort of COPD patients. We hypothesized that patient reports of irritating chemical exposures would differ depending on disease characteristics including asthma co-morbidity and COPD severity.

Methods: We conducted a cross-sectional survey of 167 clinically-confirmed COPD patients who were participants in a COPD disease management program (DMG) in a large multi-specialty medical group practice. The survey included questions about specific daily activities and associated chemical exposures likely to be irritating to the respiratory system. Participants were asked whether exposure to these activities or products bothered their breathing, whether they avoided them or took additional medications to treat symptoms when exposed to them.

Results: More than half of the COPD patients surveyed reported that certain common dusty activities (sweeping, vacuuming, dusting), and exposures to cigarette smoke, wood smoke, vehicle exhaust, cleaning products, perfumes and other scented products (scented candles, insect spray, hair products) adversely affected their breathing. There was evidence that COPD patients with an asthma diagnosis respond more to volatile organic compounds and those with more severe disease were more likely to report being bothered by particulate exposures.

Conclusions: Common environmental exposures may adversely affect COPD patients by increasing their use of rescue medications and/or their risk of clinical exacerbation; these exposures may also lower quality of life when patients alter their activities to protect themselves from such exposures.
\end{abstract}

Keywords: COPD, Triggers, Symptoms, Asthma, Environmental exposures

\section{Background}

Chronic Obstructive Pulmonary Disease (COPD) affects over 10 million people in the United States, is the third leading cause of death and is responsible for over $\$ 15$ billion in health care costs each year [1]. Tobacco smoking is the primary cause of COPD [2,3], although air pollution and occupational exposures to a number of hazardous chemicals are also important preventable causes [4-11]. It has long been recognized that in the clinical management of COPD, the most important strategy is preventing the occurrence of acute episodes of COPD exacerbation [12, 13], followed by rapid medical

\footnotetext{
* Correspondence: Susan_Sama@uml.edu

'Department of Work Environment, The University of Massachusetts Lowell, Lowell, MA 01854, USA

${ }^{2}$ Reliant Medical Group, Research Department, Worcester, MA 01605, USA
}

response when exacerbations do occur [14]. It is thought that the most important trigger of COPD exacerbation is respiratory infection $[15,16]$, although there is also good evidence that urban air pollution can also increase risk of exacerbations [17]. Environmental tobacco smoke may also be a COPD trigger [18]. Beyond these three factors, little is known about other preventable triggering exposures.

At least two lines of evidence suggest that there may be environmental chemical exposures (other than urban air pollution and tobacco smoke) which increase the risk of COPD exacerbation. First, it is likely that the mechanism by which urban air pollution triggers exacerbations involves inflammatory processes which also underlie other health endpoints including asthma, bronchial hyperreactivity, acute loss of pulmonary function and cardiovascular disease. 
Under this assumption, it seems reasonable that other chemical exposures which act through respiratory inflammation and irritation pathways might also trigger COPD exacerbations. These might include volatile organic compounds and fine particulates in indoor air. There are a large number of such chemicals identified as triggers for asthma attacks [19], and we hypothesize that asthmagens - and particularly irritant asthmagens may also act as triggers of COPD exacerbations in susceptible patients. The second reason to investigate possible environmental chemical triggers of COPD exacerbation is that patients and their clinical care providers frequently recommend avoiding certain chemical exposures (household cleaning products, strong odors, gas fumes, dust) because they may trigger exacerbations, despite the fact that little or no formal evidence exists to support these recommendations $[20,21]$. In focus groups of COPD patients (described further below), many expressed well-formed opinions about chemical exposures and activities which they seek to avoid in order to manage their disease and reduce risk of exacerbation which requires treatment with antibiotics and/or steroids. Patients and their providers often discuss strategies to avoid "flares" of symptoms - milder than full-blown exacerbations, but which often lead to increased use of rescue medications.

Asthma is a common co-morbidity with COPD [22] and we hypothesized that COPD patients who also had asthma might report different environmental irritants than COPD patients without asthma. We further hypothesized that as the course of COPD progresses, patients may change their sensitivities to environmental exposures either because these sensitivities may be modified by chronic airways inflammation and/or because their increasingly debilitating disease may limit their activities and therefore also their opportunities to be exposed to different chemicals. For example, once a patient can no longer do heavy housecleaning, their exposures to certain cleaning chemicals would be expected to decrease. To investigate potential effect modification by COPD severity, we used the standard GOLD classification [23].

As a part of a larger study of COPD exacerbation, we surveyed participants enrolled in the COPD disease management group (DMG) of a large medical group practice. The participants were administered a mailed questionnaire soliciting their input on exposures and activities which made their breathing worse. The objective of this paper is to summarize the findings of this investigation of self-reported environmental exposures reported by COPD patients to worsen their breathing symptoms. We also sought to identify patient characteristics (asthma comorbidity and COPD severity) which may affect sensitivity to different potentially triggering exposures.

\section{Methods}

All study materials and protocols were approved by the Reliant Medical Group Institutional Review Board.

\section{Patient population}

The study population was drawn from a large medical group practice in central Massachusetts. The area centers on Worcester County (population 785,000), comprising 62 towns and the city of Worcester, the third largest city in New England with a population of 175,454 . As a part of its efforts to improve patient quality of life, compliance with care guidelines and control costs, the group medical practice maintains and staffs a COPD DMG. Patients are enrolled into the group by pulmonologists or primary care physicians after a diagnosis of COPD is made based on symptoms and spirometry. These patients are followed closely through periodic telephone contacts with a nurse, as well as clinic visits. Routine calls are made by a DMG nurse to all patients at least once every 4-6 months; more frequent calls are made if patients have unstable COPD or are experiencing frequent exacerbations. The purpose of the DMG is to educate patients and teach them to properly manage their disease with the overall goal of reducing the frequency and severity of their exacerbations, thus slowing their disease progression.

We invited participation from patients who were DMG members and who had consented to participate in an ongoing study of COPD exacerbation. All had received a physician's diagnosis of COPD, had received at least one antibiotic prescription in the 3 years prior to study enrollment; had experienced at least one exacerbation in the 15 month study period; and had no other lung diseases (e.g., interstitial lung disease, lung cancer, diffuse bronchiectasis) except asthma which is often misdiagnosed in COPD patients [22].

COPD severity was characterized using the GOLD (Global Initiative for Chronic Obstructive Lung Disease) stages [24]. The GOLD stages are: stage I (mild) FEV1/ FVC $<0.70$ and $\mathrm{FEV}_{1} \geq 80 \%$ of normal; Stage II (moderate) $\mathrm{FEV} 1 / \mathrm{FVC}<0.70$ and $\mathrm{FEV}_{1} 50-79 \%$ of normal; Stage III (severe) FEV1/FVC $<0.70$ and $\mathrm{FEV}_{1} 30-49 \%$ of normal; and Stage IV (very severe) FEV1/FVC $<0.70$ and $\mathrm{FEV}_{1}<30 \%$ normal, or $<50 \%$ normal with chronic respiratory failure present. The majority of these patients had COPD signs and symptoms meeting GOLD stages I through IV. However patients referred to the DMG with symptoms of COPD and normal $\mathrm{FEV}_{1} / \mathrm{FVC}$ ratios were also included for study. Surveys were mailed to 167 eligible DMG members. The cover letter requested 
that patients complete the survey and mail it back or call the study nurse for telephone administration of the survey. The research nurse called patients who did not return their surveys or call to have them administered by phone. Patients were compensated $\$ 20$ for completing the survey.

\section{Focus groups}

We conducted 2 focus groups of patients recruited from the DMG. The first focus group was used to review our a priori list of products and activities that might be COPD triggers, and to add others if needed. The second focus group was used to pilot the exposure survey for readability and finalize the survey format. Comments and suggestions from patients were incorporated into our final survey.

\section{Surveys}

We developed a questionnaire organized into three main sections: 1) physical activities, 2) chemical exposures and 3) non-chemical triggers of COPD (such as upper respiratory tract infections, exertion and weather). The questionnaire was designed to collect data on relevant activities of daily living and exposures that might be associated with irritants and other potential triggers of COPD flares or exacerbations. A candidate list of activities and exposures was initially developed from Relationships of Indoor, Outdoor, and Personal Air (RIOPA) and National Human Exposure Assessment Survey (NHEXAS) questionnaires and workplace exposures were based largely on the American Thoracic Society (ATS) and European Respiratory Society questionnaires (including the vapors, dust, gas, fumes questions) [25-27].

This list was then narrowed by identifying the subset that were likely to be found in home and community settings where patients were likely to go (stores, restaurants, gas stations, etc.). The candidate list included activities and exposures associated with agents in the following categories: known asthmagens, respiratory irritants, "non-specific dusts" as referred to by the American Thoracic Society vapor dust gas fume questions, volatile organic compounds, combustion aerosols, bioaerosols and tobacco smoke [10, 11, 19, 28-31].

For each of the activities (Appendix), exposures and products we asked the following questions: would exposure to any of these activities (exposures, products) bother your breathing or make it harder to breathe? Do you avoid exposure to this activity? Have you ever needed to start antibiotics or steroids after exposure to this product? If you do get exposed to this activity, how do you handle it? (Possible responses: I remove myself from the activity; I increase my daily rescue medications; Other (Please Specify)). We chose a range of possible responses from the mildest - that the exposure "bothered" their breathing to the clinically relevant reporting of having to use additional medications to regain the ability to breathe comfortably. Data presented below include patients who answered yes to any of these questions indicating that these activities or products trigger symptoms that worsen their breathing. We refer to anything that engendered an affirmative on the spectrum of adverse responses (from bothered to taking additional medications) as a "symptom trigger".

\section{Patient susceptibility}

We hypothesized that COPD patients might report different types and severities of adverse responses to irritant exposures depending on characteristics of their underlying disease. Specifically, we hypothesized that: 1) those patients with more severe disease as defined by the GOLD criteria might have different types of responses to triggering exposures than those with less severe disease; and 2) COPD patients who also had received a diagnosis of asthma might show a different pattern of responses to irritant and sensitizing exposures than those without an asthma diagnosis. We grouped GOLD stages I and II - mild and moderate COPD versus III and IV - severe and very severe. Post-bronchodilator spirometry was missing for 12 patients, and for these we used their baseline spirometry to assign their GOLD stage. The standard ATS survey questions on doctor-diagnosed asthma were used to identify COPD patients who also had asthma: "Have you ever had asthma? If yes, was it confirmed by a doctor?" [32].

\section{Data analysis}

Data were entered into an ACCESS database, edited and cleaned. The final dataset was analyzed in SAS (SAS Institute Inc., Version 9.3, Cary, NC,). Cleaned survey data were exported into SAS. The potential modifying effects of COPD severity or asthma diagnosis were investigated by calculating prevalence ratios comparing the frequency of reporting a particular exposure as bothersome in one group (severe/very severe COPD or those with asthma) versus a comparison population (mild/moderate COPD, no asthma).

\section{Results}

Surveys were mailed to 167 COPD patients, and we received responses from 145 (87\%). The mean age of the respondents was 72 years, $56 \%$ were female and almost all were white (Table 1). Approximately two thirds of patients had severe or very severe COPD (GOLD Stages 3 or 4). Ninety seven percent of patients had a smoking history with an average of 52 pack years. More than half were on 
Table 1 Characteristics of COPD patients surveyed

\begin{tabular}{|c|c|c|c|}
\hline & \multirow{2}{*}{$\begin{array}{l}\text { Overall } \\
(n=145)\end{array}$} & \multicolumn{2}{|c|}{ Asthma diagnosis } \\
\hline & & No $(n=87)$ & Yes $(n=58)$ \\
\hline Age (years) & $71.6(8.8)^{a}$ & $71.9(9.0)$ & $71.2(8.7)$ \\
\hline Female & $56 \%(82)^{b}$ & $59 \%(51)$ & $53 \%(31)$ \\
\hline Race: White & $97 \%(140)$ & $99 \%(86)$ & $93 \%(54)$ \\
\hline Black & $2.1 \%(3)$ & $1.2 \%(1)$ & $3.5 \%(2)$ \\
\hline Other & $1.4 \%(2)$ & $0 \%$ & $3.5 \%(2)$ \\
\hline \multicolumn{4}{|l|}{ GOLD stage } \\
\hline $1 \mathrm{Mild}$ & $2 \%(3)$ & $3.5 \%(3)$ & $0 \%$ \\
\hline 2 Moderate & $23 \%(33)$ & $24 \%(21)$ & $21 \%(12)$ \\
\hline 3 Severe & $51 \%(73)$ & $51 \%(44)$ & $50 \%(29)$ \\
\hline 4 Very severe & $16 \%(23)$ & $18 \%(16)$ & $12 \%(7)$ \\
\hline $\begin{array}{l}\text { Normal } \mathrm{FEV}_{1} / \mathrm{FVC} \text { with } \\
\text { COPD Symptoms }\end{array}$ & $7 \%(10)$ & $2.3 \%(2)$ & $14 \%(8)$ \\
\hline Inadequate spirometry ${ }^{c}$ & $2 \%(3)$ & $1.2 \%(1)$ & $3.5 \%(2)$ \\
\hline \multicolumn{4}{|l|}{ Smoking status } \\
\hline Current & $16 \%(22)$ & $21 \%(18)$ & $7.7 \%(4)$ \\
\hline Ex & $81 \%(118)$ & $80 \%(70)$ & $83 \%(48)$ \\
\hline Never & $4.1 \%(6)$ & $0 \%$ & $10 \%(6)$ \\
\hline Pack years & $52(32.3)^{a}$ & $54.9(26.9)$ & $47.6(39.2)$ \\
\hline Regular home oxygen & $54 \%(76)$ & $60 \%(50)$ & $45 \%(26)$ \\
\hline Regular nebulizer use & $79 \%(109)$ & $76 \%(63)$ & $84 \%(46)$ \\
\hline $\begin{array}{l}\mathrm{FEV}_{1} \text { improvement } \\
\text { post-bronchodilator } \geq 15 \%\end{array}$ & $18 \%(25)$ & $18 \%(15)$ & $19 \%(10)$ \\
\hline
\end{tabular}

${ }^{\mathrm{a}}$ Mean (std. deviation)

${ }^{\mathrm{b}}$ Percent (n)

${ }^{\mathrm{C} E x c l u d e d}$ from analyses comparing mild/moderate versus severe/very

severe COPD some form of oxygen therapy to reduce or prevent the complications of hypoxemia. Forty percent of this population of COPD patients reported ever having a doctor diagnosis of asthma. Asthmatics and non-asthmatic participants were fairly similar in most respects. However, fourteen percent of the asthmatics had normal $\mathrm{FEV}_{1} / \mathrm{FVC}$ ratios compared to $2 \%$ of the non-asthmatics $(p=0.007)$. In addition asthmatics were less likely to be smokers. For example, about $8 \%$ the percent of asthmatics reported current smoking compared to $21 \%$ of non-asthmatics $(p=0.04)$.

A wide range of activities and products were reported by patients as making their breathing worse (Fig. 1 shows those reported by at least $50 \%$ of the population - see Appendix for the complete set). These were generally either activities which generated particulates such as sweeping or vacuuming, or dusting, or else they involved exposure to volatile organic compounds such as paint thinner, perfumes, and scented candles. The smoking of tobacco products (active or passive) and sweeping or vacuuming were the most frequently reported $(74,70 \%$ respectively) symptom triggers, followed by paint thinner (62\%), cleaning supplies $(60 \%)$ and wood smoke (60\%).

The frequency of reporting different symptom triggers varied depending on both disease severity and on whether or not the patient reported a diagnosis of asthma along with their COPD (Figs. 2 and 3). Those COPD patients with disease categorized as severe or very severe were at least $50 \%$ more likely (prevalence ratio > 1.5) to report being adversely affected by several activities involving

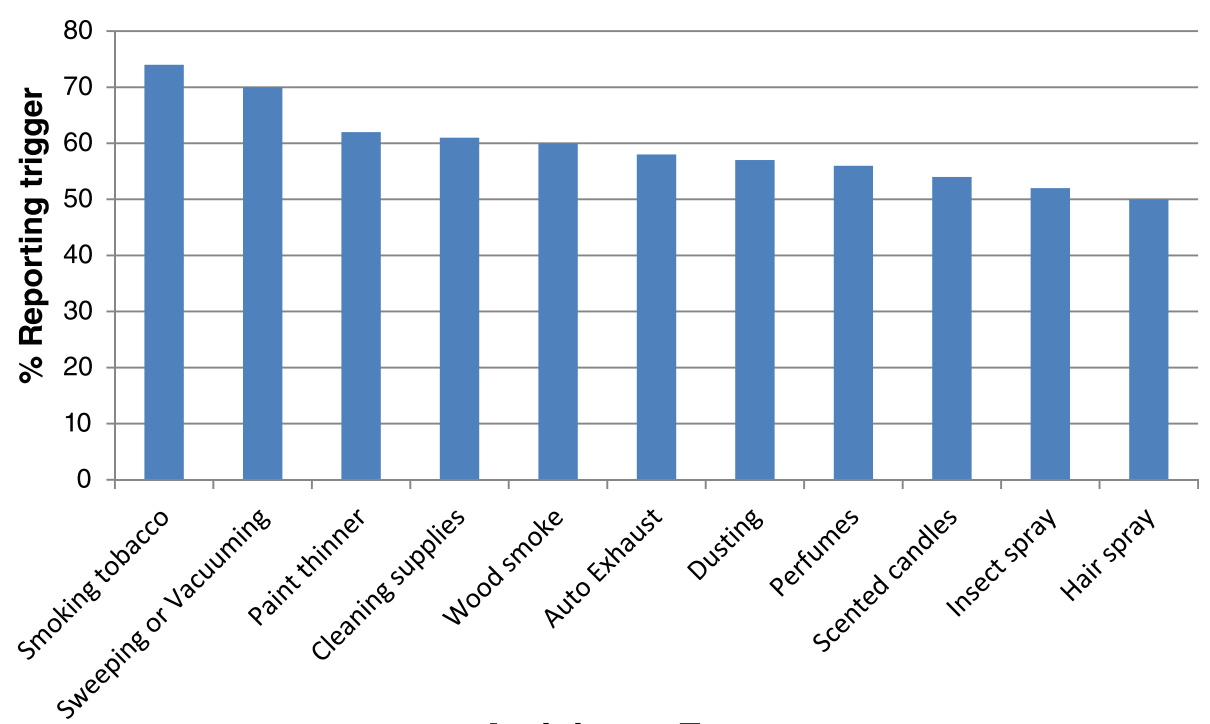

Activity or Exposure

Fig. 1 Self-reported symptom triggers affecting at least $50 \%$ of COPD patients 


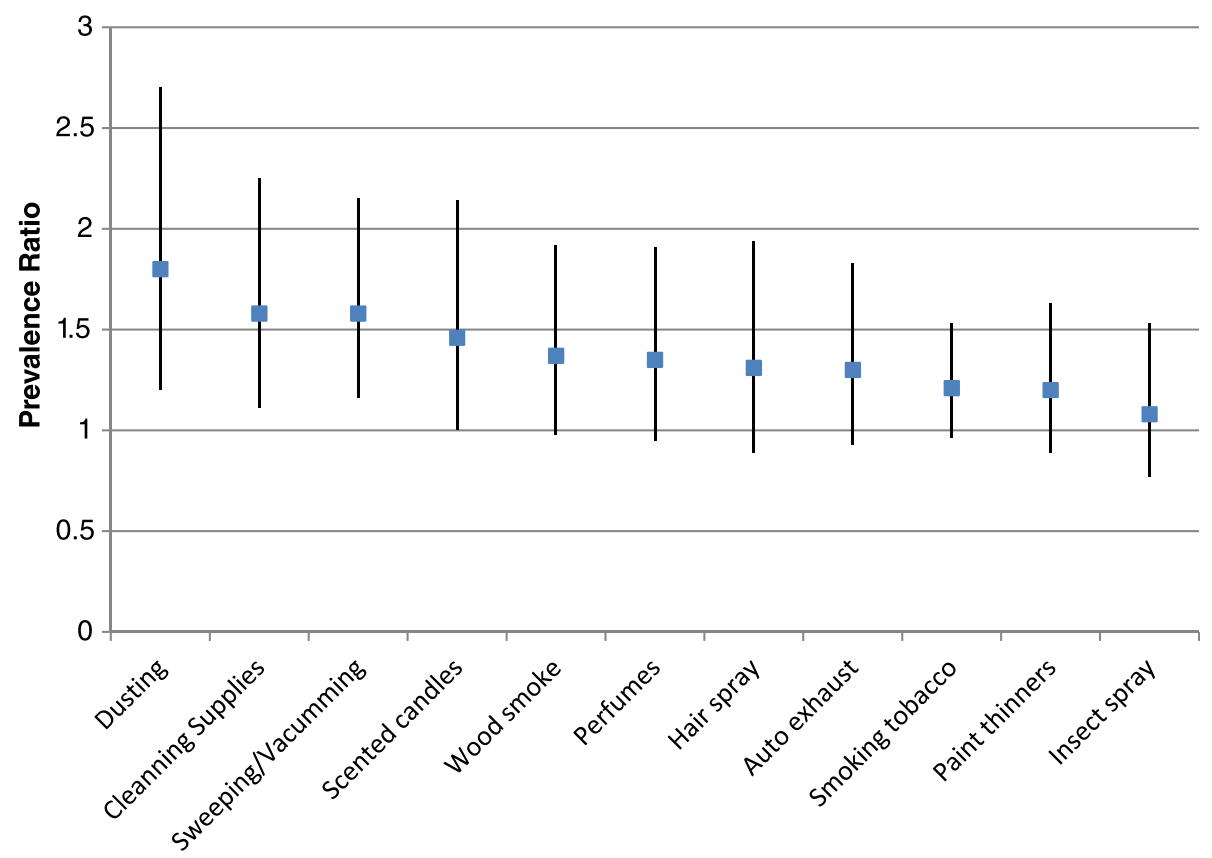

Fig. 2 Self-reported symptom triggers. Prevalence ratios for severe/very severe versus mild/moderate COPD . . Mild/Moderate: COPD diagnosis normal FEV/FVC Ratios and Gold Stages 1, 2; Severe/Nery Severe COPD includes Gold Stages 3 and 4. Error bars represent $95 \%$ confidence intervals

exposure to particulates - dusting, cleaning with cleaning supplies, sweeping and vacuuming, than those with mild or moderate disease. Several other exposures including scented candles and wood smoke seemed to be more frequently reported by those with more severe COPD.
COPD patients who reported that they had been told by a doctor that they had asthma reported a somewhat different pattern of symptom triggers. They were more likely to report that exposures to several volatile organic compounds triggered their symptoms than those

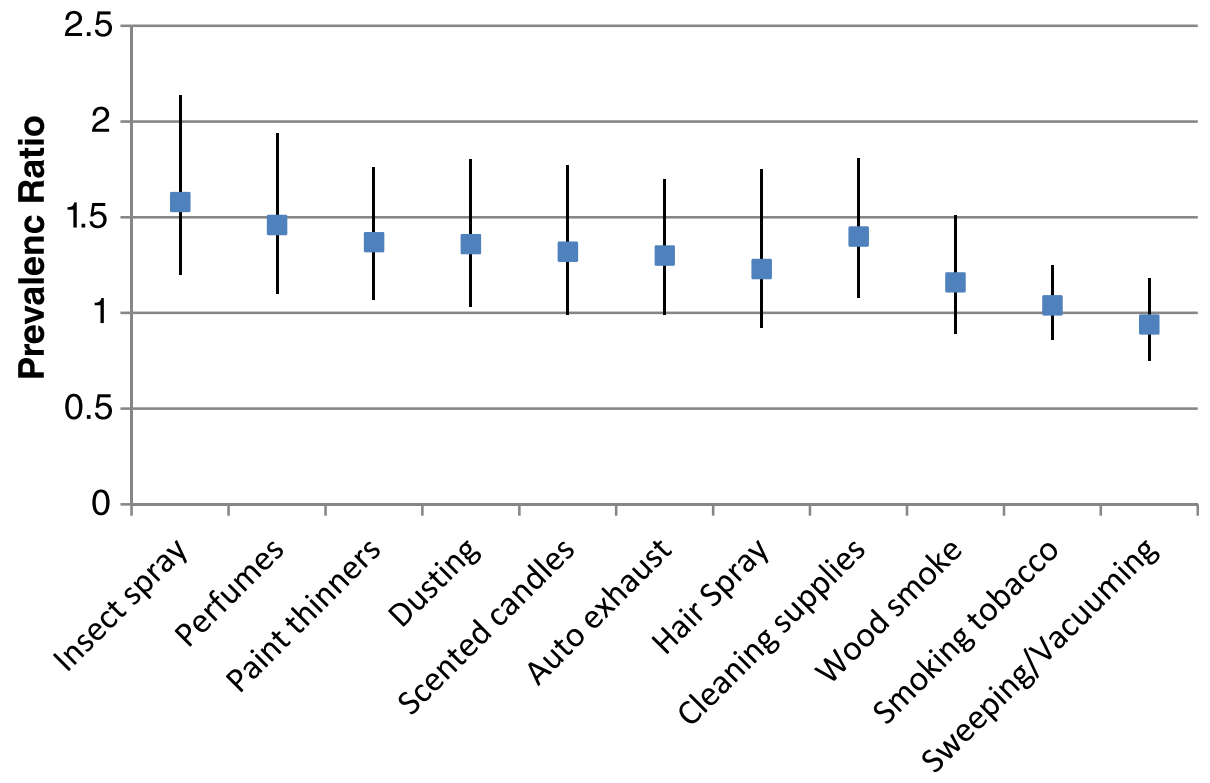

Fig. 3 Self-reported symptom triggers comparing those with and without doctor diagnosed asthma*. ${ }^{*}$ Patient responded yes to both questions: Have you ever had asthma? Was it confirmed by a doctor? Error bars represent $95 \%$ confidence intervals 
without asthma diagnoses. These exposures included insect sprays, perfumes, cleaning supplies and paint thinner (Fig. 3).

The most clinically significant response to an exposure or activity was having to take additional medications to control symptoms. Several exposures were found to frequently require this level of response by the patients (Table 2). For example, nearly one quarter of those who said they were bothered by wood smoke said that they sometimes had to use medications to control their symptoms after this exposure. About a third of the COPD patients reported that air fresheners bothered their breathing (Appendix), and of those, about one in five said they needed to use additional medications following this exposure. Perfumes and car and truck exhaust had very similar levels of symptoms and medication usage.

\section{Discussion and conclusions}

Chronic disease management has been shown to improve symptoms, quality of life and other outcomes (emergency room visits and inpatient admissions) in COPD patients [12, 13, 33]. It is important that patients know and control triggers and symptoms of COPD exacerbations. To date, viral respiratory infections have been understood to be the primary trigger for exacerbations, and so prevention strategies have emphasized annual flu and pneumonia vaccines. While there is good evidence for this recommendation, there is a lack of additional evidence-based prevention strategies provided to COPD patients. Disease management programs often recommend that patients identify and avoid factors that can make COPD

Table 2 Symptom triggers most frequently reported to require additional rescue medications

\begin{tabular}{|c|c|c|}
\hline Exposure/Activity & $\%(n)$ of those bothered ${ }^{a}$ & $95 \% \mathrm{Cl}^{\mathrm{b}}$ \\
\hline Wood smoke & $24.6(65)$ & $(14.8,36.9)$ \\
\hline Air fresheners & $21.7(46)$ & $(10.9,36.4)$ \\
\hline Perfume & $21.5(65)$ & $(12.3,33.5)$ \\
\hline Vehicle exhaust & $19.4(67)$ & $(10.8,30.9)$ \\
\hline Cleaning & $18.5(65)$ & $(9.9,30.0)$ \\
\hline Barbeque & $17.7(34)$ & $(6.8,34.5)$ \\
\hline Gas & $17.6(17)$ & $(3.8,43.4)$ \\
\hline Household cleaners & $17.4(69)$ & $(9.3,28.4)$ \\
\hline Markers & $16.7(18)$ & $(3.6,41.4)$ \\
\hline Dusting & $16.7(60)$ & $(8.3,28.5)$ \\
\hline Glue & $16.2(37)$ & $(6.2,32.0)$ \\
\hline Vacuuming OR sweeping & $18.8(80)$ & $(10.9,29.0)$ \\
\hline
\end{tabular}

symptoms worse. One such program, "Living Well with COPD" has a list of possible triggers [20] that contains many of the exposures that we report, but there does not appear to be any formal quantitative evidence to support these recommendations.

There are a large number of known environmental triggers of asthma attacks [19]. Many COPD patients have both a reversible and fixed component to their disease. Good clinical management of COPD seeks to limit exposures that could cause an inflammatory response, worsening the reversible obstruction. There is much less known about which substances might initiate this inflammatory response in COPD patients, but the overlap between the two diseases suggests that it is reasonable to investigate asthmagens as potential irritants for COPD patients.

Our primary inclusion criterion was membership in the DMG which was based on a clinician's judgement. However, since there were some Gold 0 subjects (normal $\mathrm{FEV}_{1} / \mathrm{FVC}$ but with COPD symptoms), we investigated the impact of excluding Gold 0 subjects, as well as three patients who were missing spirometry data and found little difference. For example in Table 2, the three most commonly reported irritants requiring additional rescue medications were wood smoke, air fresheners and perfume, which changed from 24.6 to $23.0 \%, 21.7$ to $20.9 \%$ and 21.5 to $20.6 \%$ respectively.

We stratified the analysis to investigate variations in patterns of triggers within the COPD patient population. These results suggested that not all patients respond the same way to these symptom triggers. Although the mechanism for such a response is unclear, the results suggest that perhaps COPD patients with an asthma diagnosis respond more to volatile organic compounds while those with more severe disease were more likely to report being affected by common particulate exposures.

A limitation of this investigation is that we were not studying clinical exacerbation but rather selfreported irritation of breathing and the need for rescue medication. While these self-reports are subjective and did not necessarily lead to a full-blown exacerbation, we believe that the findings are nonetheless relevant. If patients are using rescue medication, and avoiding certain environments or activities in order to protect themselves, we believe this indicates a material impact on health and quality of life that clinicians and patients will want to take seriously. The observation that asthma co-morbidity and COPD severity appeared to modify the pattern of reported triggers may suggest potential lines of research for further studies which may improve our ability to prevent environmentallytriggered exacerbations. 


\section{Appendix}

Table 3 Summary of all symptom triggers

\begin{tabular}{|c|c|c|}
\hline \multirow[b]{2}{*}{ Activity or exposure } & \multicolumn{2}{|c|}{$\begin{array}{l}\text { Percent }(n) \text { of all respondents } \\
(n=145) \text { who answered yes t }\end{array}$} \\
\hline & $\begin{array}{l}\text { "Breathing was } \\
\text { bothered" or } \\
\text { "it was harder } \\
\text { to breathe" }\end{array}$ & $\begin{array}{l}\text { Took action } \\
\text { in response } \\
\text { to exposure, } \\
\text { activity }\end{array}$ \\
\hline Having a respiratory infection or cold & 75 (108) & $81(118)$ \\
\hline $\begin{array}{l}\text { Spending time in the hot weather } \\
\text { or humidity }\end{array}$ & $81(117)$ & $87(126)$ \\
\hline $\begin{array}{l}\text { Dusty activities like sweeping, wood } \\
\text { working, raking, or using fertilizers }\end{array}$ & $64 \%(93)$ & $82(119)$ \\
\hline Shoveling or clearing snow off your car & $61 \%(88)$ & $76(110)$ \\
\hline Increase in physical activity & $72(105)$ & $77(111)$ \\
\hline $\begin{array}{l}\text { Spending time in the cold air or in } \\
\text { cold weather }\end{array}$ & $67(97)$ & $75(108)$ \\
\hline $\begin{array}{l}\text { Mowing or trimming the lawn or } \\
\text { using snow blower }\end{array}$ & $58 \%(84)$ & $73(106)$ \\
\hline Suffering from allergies & $48(70)$ & $57(82)$ \\
\hline Exercising & $63(91)$ & $67(97)$ \\
\hline $\begin{array}{l}\text { Smoking of tobacco products } \\
\text { (cigarettes, pipes, cigars or other) }\end{array}$ & $57 \%(82)$ & $74(107)$ \\
\hline Other yard work or gardening & $48 \%(71)$ & $66(96)$ \\
\hline Paint thinners and solvents & $43 \%(62)$ & $62(90)$ \\
\hline $\begin{array}{l}\text { Suffering from increased stress } \\
\text { or intense emotions }\end{array}$ & $50(72)$ & $56(81)$ \\
\hline Bug/Insect spray & $39 \%(56)$ & $52(76)$ \\
\hline $\begin{array}{l}\text { Use of a wood smoke fire } \\
\text { (pellet stove, woodstove, campfire, etc.) }\end{array}$ & $45 \%(65)$ & $60(87)$ \\
\hline Car or truck exhaust & $46 \%(67)$ & $58(84)$ \\
\hline $\begin{array}{l}\text { Having a non-respiratory virus } \\
\text { (i.e., stomach bug, flu) }\end{array}$ & $25(36)$ & $36(52)$ \\
\hline Perfumes, colognes or body sprays & $45 \%(65)$ & $56(81)$ \\
\hline Sweeping (inside or outside) & $48 \%(70)$ & $61(89)$ \\
\hline Vacuuming & $47 \%(68)$ & $61(88)_{-}$ \\
\hline $\begin{array}{l}\text { Household cleaning products } \\
\text { (cleaners, waxes, polishes) }\end{array}$ & $48 \%(69)$ & $60(87)$ \\
\hline Scented candles or incense & $40 \%(58) \mathrm{s}$ & $54(79)$ \\
\hline Hair spray or hair gel or hair mousse & $38 \%(55)$ & $50(72)$ \\
\hline $\begin{array}{l}\text { Cleaning with cleaning supplies } \\
\text { (cleaners, waxes, and polishes) }\end{array}$ & $45 \%(65)$ & $61(88)$ \\
\hline Having a sinus infection & $39(57)$ & $48(69)$ \\
\hline Dusting & $41 \%(60)$ & $57(82)$ \\
\hline $\begin{array}{l}\text { Glues or epoxy (for example during } \\
\text { hobbies or art class) }\end{array}$ & $26 \%(37)$ & $41(59)$ \\
\hline Animals or pets & $19 \%(28)$ & $34(49)$ \\
\hline Barbequing, frying or sautéing food & $23 \%(34)$ & $37(54)$ \\
\hline Nail polish or nail polish remover & $28 \%(42)$ & $39(57)$ \\
\hline
\end{tabular}

Table 3 Summary of all symptom triggers (Continued)

\begin{tabular}{lcc}
\hline $\begin{array}{l}\text { Swimming or around an indoor } \\
\text { or outdoor pool }\end{array}$ & $28 \%(41)$ & $42(61)$ \\
$\begin{array}{l}\text { Paint (for example hobbies or art class) } \\
\text { or white out }\end{array}$ & $32 \%(47)$ & $47(68)$ \\
$\begin{array}{l}\text { Air fresheners (Plug in Wall } \\
\text { dispensers, sprays, etc.) }\end{array}$ & $32 \%(46)$ & $44(64)$ \\
$\begin{array}{l}\text { Furniture spray or polish } \\
\text { Filling the car with gas or diesel fuel }\end{array}$ & $32 \%(47)$ & $45(65)$ \\
$\begin{array}{l}\text { Scented laundry products (detergents, } \\
\text { laundry softeners or drier sheets) }\end{array}$ & $20 \%(29)$ & $34(50)$ \\
Cooking with a gas stove & $12 \%(17)$ & $25(36)$ \\
Spray deodorant & $23 \%(33)$ & $35(51)$ \\
Picking up or wearing dry cleaning & $6 \%(9)$ & $19(27)$ \\
$\begin{array}{l}\text { Writing or drawing with felt tipped } \\
\text { markers or highlighters } \\
\text { Hand sanitizers (liquid, gel, wipes) }\end{array}$ & $12 \%(18)$ & $21(31)$ \\
Cosmetics & $10 \%(15)$ & $19(27)$ \\
Copier machine or printer & $10 \%(14)$ & $17(25)$ \\
\hline
\end{tabular}

aeported yes to at least one of the following questions: 1) Do you avoid exposure to this activity? 2) Have you ever needed to start Antibiotics or Steroids after exposure to this product? 3) If you do get exposed to this activity, how do you handle it? a) I remove myself from the activity. b) I increase my daily rescue medications. c) Other (Please specify)

\section{Abbreviations}

ATS: American Thoracic Society; COPD: Chronic obstructive pulmonary disease; DMG: Disease Management Group.

\section{Competing interests}

The authors declare that they have no competing interests.

\section{Authors' contributions}

SRS had full access to all of the data in the study and takes responsibility for the integrity of the data and the accuracy of the data analysis. SRS and DK contributed to the study conception and design, analysis and interpretation of data, drafting the manuscript for important intellectual content, as well as reading and approving the final manuscript. $R G$ and $R D$ contributed to study analysis and interpretation of the data and review of the manuscript. RR contributed to the study conception and design and interpretation of data analysis and review of final manuscript for important intellectual content. All authors read and approved the final manuscript.

\section{Acknowledgements}

We thank Kathy Allain, Brenda Kniskern, Margalit Lai, Christine Andersson and Devi Sundaresan (Reliant Medical Group) for superb project management and the COPD patients who generously agreed to participate in our study. This work was supported by [1R21ESO17849] from the National Institute of Environmental Health Sciences and [T01-OH008424-10] from National Institute of Occupational Safety and Health, National Institutes of Health.

Received: 9 July 2015 Accepted: 8 December 2015

Published online: 23 December 2015

\section{References}

1. National Heart, Lung, and Blood Institute. Morbidity and mortality chartbook on cardiovascular, lung and blood diseases. In: U.S. Department of Health and Human Services, Public HEalth Service, National Institutes of Health. 2009.

2. Holt PG. Immune and inflammatory function in cigarette smokers. Thorax. 1987;42:241-9. 
3. Tager IB, Ngo L, Hanrahan JP. Maternal smoking during pregnancy. Effects on lung function during the first 18 months of life. Am J Respir Crit Care Med. 1995;152:977-83.

4. Global Strategy for the Diagnosis, Management and Prevention of COPD (Updated 2015). [http://www.goldcopd.org]. Accessed 30 November 2015.

5. Sunyer J, Basagana X. Particles, and not gases, are associated with the risk of death in patients with chronic obstructive pulmonary disease. Int J Epidemiol. 2001;30(5):1138-40

6. Anto JM, Vermeire P, Vestbo J, Sunyer J. Epidemiology of chronic obstructive pulmonary disease. Eur Respir J. 2001;17(5):982-94.

7. Becklake MR. Chronic airflow limitation: its relationship to work in dusty occupations. Chest. 1985:88(4):608-17.

8. Becklake MR. Occupational exposures: evidence for a causal association with chronic obstructive pulmonary disease. Am Rev Respir Dis. 1989:140(3 Pt 2):S85-91.

9. Blanc PD, Eisner MD, Balmes JR, Trupin L, Yelin EH, Katz PP. Exposure to vapors, gas, dust, or fumes: assessment by a single survey item compared to a detailed exposure battery and a job exposure matrix. Am J Ind Med. 2005:48(2):110-7.

10. Blanc PD, Iribarren C, Trupin L, Earnest G, Katz PP, Balmes J, et al. Occupational exposures and the risk of COPD: dusty trades revisited. Thorax. 2009;64(1):6-12

11. Blanc PD, Menezes AM, Plana E, Mannino DM, Hallal PC, Toren K, et al. Occupational exposures and COPD: an ecological analysis of international data. Eur Respir J. 2009;33(2):298-304.

12. Bourbeau J. Self-management interventions to improve outcomes in patients suffering from COPD. Expert Rev Pharmacoecon Outcomes Res. 2004;4(1):71-7.

13. Bourbeau J, Collet JP, Schwartzman K, Ducruet T, Nault D, Bradley C. Economic benefits of self-management education in COPD. Chest. 2006;130(6):1704-11

14. Bourbeau J, Ford G, Zackon H, Pinsky N, Lee J, Ruberto G. Impact on patients' health status following early identification of a COPD exacerbation. Eur Respir J. 2007;30(5):907-13.

15. Wedzicha JA, Donaldson GC. Exacerbations of chronic obstructive pulmonary disease. Respir Care. 2003:48(12):1204-13. discussion 1213-1205.

16. Wedzicha JA, Seemungal TA. COPD exacerbations: defining their cause and prevention. Lancet. 2007:370(9589):786-96.

17. Desqueyroux H, Pujet JC, Prosper M, Le Moullec Y, Momas I. Effects of air pollution on adults with chronic obstructive pulmonary disease. Arch Environ Health. 2002;57(6):554-60.

18. Garcia-Aymerich J, Farrero E, Felez MA, Izquierdo J, Marrades RM, Anto JM. Risk factors of readmission to hospital for a COPD exacerbation: a prospective study. Thorax. 2003;58(2):100-5.

19. Bernstein IL, Chan-Yeung M, Malo JL, Bernstein DI. Asthma in the Workplace. 2nd ed. New York: Marcel Dekker, Inc.; 1999.

20. Living Well with COPD. [www.livingwellwithcopd.com]. Accessed 14 December 2015

21. Nault D. Patient self-management: A key to success for COPD management Can Respir J. 2007;14:19A-20

22. Zeki AA, Schivo M, Chan A, Albertson TE, Louie S. The Asthma-COPD Overlap Syndrome: A Common Clinical Problem in the Elderly. J Allergy (Cairo). 2011:2011:861926. doi:10.1155/2011/861926.

23. Standards for the diagnosis and care of patients with chronic obstructive pulmonary disease. American Thoracic Society. Am J Respir Crit Care Med. 1995;152(5 Pt 2):S77-121.

24. Global strategy for the diagnosis, managment and prevention of COPD 2014. [http://www.goldcopd.org]. Accessed 14 December 2015.

25. Clayton CA, Pellizzari ED, Quackenboss JJ. National Human Exposure Assessment Survey: analysis of exposure pathways and routes for arsenic and lead in EPA Region 5. J Expo Anal Environ Epidemiol. 2002;12(1):29-43.

26. Clayton CA, Pellizzari ED, Whitmore RW, Perritt RL, Quackenboss JJ. National Human Exposure Assessment Survey (NHEXAS): distributions and associations of lead, arsenic and volatile organic compounds in EPA region 5. J Expo Anal Environ Epidemiol. 1999;9(5):381-92

27. Weisel CP, Zhang J, Turpin BJ, Morandi MT, Colome S, Stock TH, et al. Relationships of Indoor, Outdoor, and Personal Air (RIOPA). Part I. Collection methods and descriptive analyses. Res Rep Health Eff Inst. 2005;130 Pt 1:1-107. discussion 109-127.

28. Burney PG, Luczynska C, Chinn S, Jarvis D. The European Community Respiratory Health Survey. Eur Respir J. 1994;7(5):954-60.
29. Burge PS. Occupation and chronic obstructive pulmonary disease (COPD). Eur Respir J. 1994;7(6):1032-4.

30. Elliott L, Longnecker MP, Kissling GE, London SJ. Volatile organic compounds and pulmonary function in the Third National Health and Nutrition Examination Survey, 1988-1994. Environ Health Perspect. 2006;114(8):1210-4.

31. Heldal KK, Halstensen AS, Thorn J, Eduard W, Halstensen TS. Airway inflammation in waste handlers exposed to bioaerosols assessed by induced sputum. Eur Respir J. 2003;21(4):641-5.

32. Standardization of spirometry, 1994 Update. American Thoracic Society. Am J Respir Crit Care Med. 1995:152(3):1107-1136.

33. Bourbeau J, Julien M, Maltais F, Rouleau M, Beaupre A, Begin R, et al. Reduction of hospital utilization in patients with chronic obstructive pulmonary disease: a disease-specific self-management intervention. Arch Intern Med. 2003;163(5):585-91.

\section{Submit your next manuscript to BioMed Central and we will help you at every step:}

- We accept pre-submission inquiries

- Our selector tool helps you to find the most relevant journal

- We provide round the clock customer support

- Convenient online submission

- Thorough peer review

- Inclusion in PubMed and all major indexing services

- Maximum visibility for your research

Submit your manuscript at www.biomedcentral.com/submit
Biomed Central 